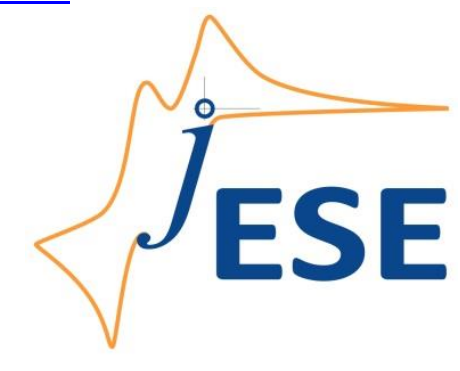

Open Access : : ISSN 1847-9286

www.jESE-online.org

Original scientific paper

\title{
Electrosynthesis of gold nanocomposites based on a copolymer of 1-vinyl-1,2,4-triazol with crotonic acid
}

\author{
Serzhik H. Sargsyan ${ }^{1, \bowtie}$, Artur S. Sargsyan², Tatevik S. Sargsyan², \\ Karina M. Khizantsyan ${ }^{1}$, Ida G. Aghajanyan ${ }^{1}$ and Karine S. Margaryan ${ }^{2}$ \\ ${ }^{1}$ National Polytechnic University of Armenia, Teryan 105, 0009 Yerevan, Armenia \\ ${ }^{2}$ Yerevan State Medical University after Mkhitar Heratsi, Koryun 2, 0025 Yerevan, Armenia \\ Corresponding author: ${ }^{凶}$ artsar86@mail.ru
}

Received: November 28, 2021; Accepted: January 11, 2022; Published: January 25, 2022

\begin{abstract}
In this work, we have synthesized and discussed the results of electrosynthesis of metalpolymer nanocomposites of gold. Nanocoatings were made on pure iron and steel electrodes by combining the process of electropolymerization of 1-vinyl-1.2.4-triazole with crotonic acid and cathodic deposition of gold. Using UV, IR and atomic absorption spectroscopies, $X$-ray phase analysis, as well as thermogravimetric and elemental analyses, the structure and composition of the synthesized nanocomposites and nanocomposite coatings were studied.
\end{abstract}

\section{Keywords}

Electrolysis; nanocomposite film; electropolymerization; medicine; thermal stability

\section{Introduction}

Nanocomposite materials containing gold nanoparticles have unique properties and their development is promising for medicine, nanophotonics and catalysis [1-4].

Electrosynthesis and study of the properties of functional polymers and on this basis obtained nanomaterials, is the most rapidly developing area of modern chemical science. As noted in [2-12], nanomaterials are used in medicine as antibacterial drugs, systems for targeted delivery of contrast agents and drugs, biosensors, and other biomedical purposes.

For wider use in medicine, nanomaterials must have thromboresistance, hydrophilicity, biological activity, biocompatibility, etc., and also, due to the presence of functional groups they must have an ability to bind to various substances, including drugs. These properties are characteristic for copolymers of 1-vinyl-1.2.4-triazole (VT) with acrylic acid, which are poorly studied, but promising polymers for medical use [13-16]. Materials based on nanoparticles of various metals are often used in medicine. They are used as coverings for wounds, various medical devices, surgical masks, etc. [17-20]. Among metal nanoparticles, gold nanoparticles have the highest antibacterial and antiviral activity $[20,21]$. 
The synthesis of new functional thrombo-resistant, non-toxic polymeric materials with gold nanoparticles makes it possible to expand the area of their application, as well as to increase the range of materials used in pharmaceuticals when creating new dosage forms. The properties of these nanocomposites substantially depend on both the nature of the stabilizing polymer matrix and the conditions for the formation of nanoparticles. As a polymer matrix, VT polymers and copolymers can be used since they are non-toxic ( $L D 50>3000 \mathrm{mg} \mathrm{kg}^{-1}$ ) and have high film formation ability, solubility, and biocompatibility $[22,23]$. In [22,24], a possibility of electrochemical formation of metal-containing nanocomposites and nanocomposite coatings based on vinylazole copolymers has already been reported.

The synthesis and research of nanostructured functional systems, including nanocatalytic ones, are the priority areas of modern science. Due to their unusual physical and chemical properties, which differ from those of bulk metal, metal nanoparticles have a wide variety of potential applications in the field of catalysis, biomedicine, optics, electronics, etc. [25-35]. Metal nanoparticles are thermodynamically unstable, and in a relatively pure individual form, they can be obtained only when fixed on a solid as immobile support. To obtain such particles on an electrically conductive carrier, the electrochemical method is widely used in various versions of its implementation [36].

Nanocomposite materials containing gold nanoparticles have unique properties, and their use is promising for medicine [27-29]. Polymer nanocomposites containing zero-valent gold are effective antimicrobial and antiviral agents. The high antibacterial activity of gold nanoparticles is due to its developed surface. In addition, nanoparticles are small enough and capable of penetrating cell membranes and affecting intracellular processes.

In this work, we discuss the results of electrosynthesis of metal-polymer nanocomposites and their coatings on pure iron and steel electrodes when electrochemical (co) polymerization of solid solution with crotonic acid (CA) is combined with the cathodic discharge of metal.

\section{Experimental}

The electrochemical initiation of polymerization was carried out in a glass electrolyzer without a diaphragm. Electrosynthesis in galvanostatic and potentiostatic modes was carried out using a ПИ-50.1 potentiogalvanostat with a ПР-8 programmer (Russia). The thickness of films was determined by micrometric and magnetic methods. Elemental analysis was performed on a FLASH EA 1112 series analyzer. The IR spectra of the polymers were recorded on Specord M-80 and Bruker Vertex 70 spectrometers using fine powders pressed into tablets with $\mathrm{KBr}$. Absorption spectra were recorded on a Perkin Elmer Lambda 35 UV/VIS spectrophotometer. The metal content in the composites was determined by elemental and atomic absorption analysis on a Perkin Elmer Analyst 200 spectrometer. The distribution of gold nanoparticles was established on a Leo 906 E TEM (Germany). Thermogravimetric analysis was performed on an MOM derivatograph (Hungary), the temperature rise rate was $5{ }^{\circ} \mathrm{C} \mathrm{min}-1$, while electrical conductivity was measured using a standard E6-13A teraohmmeter. As electrodes, we used pure ARMCO iron with an iron content of $99.92 \%$ and St-3 with an iron content of $97 \%$.

1-vinyl-1.2.4-triazole was obtained and purified by the method described in [37], and crotonic acid was purified by sublimation.

\section{General method of electrosynthesis of nanocomposites and coatings}

In a glass electrolytic cell with a capacity of $50 \mathrm{ml}$, electrolysis was carried out $[E=-0.1 \ldots-1.2 \mathrm{~V}$ vs. $\mathrm{Ag} / \mathrm{AgCl}, j=1-15 \mathrm{~mA} \mathrm{~cm}^{-2}$ ] in aqueous or water-ethanol solutions (bi-distilled water and distilled 
ethanol) containing $0.5-1 \mathrm{~mol} \mathrm{l}^{-1}$ of 1-vinyl-1.2.4-triazole, $0.5-1 \mathrm{~mol} \mathrm{l}^{-1}$ of crotonic acid, 1.5 - $4 \mathrm{mmol} \mathrm{I}^{-1} \mathrm{HAuCl}_{4}, 0.02$ - $0.05 \%$ 4-tert-butylperoxy-4-oxobutanoic acid (TBOBA), and in some cases 0.05 to $0.07 \mathrm{wt} . \%$ chitosan. A pure iron or steel plate with an area of $1-2 \mathrm{~cm}^{2}$ was used as the working electrode (cathode), and a platinum or glassy carbon (SU-12, SU-20) plate with the same area was used as the anode. At high current densities $j>10 \mathrm{~mA} \mathrm{~cm}^{-2}$, the nanocomposite was deposited onto the electrolyzer floor. After the end of electropolymerization, the electrode package was removed, the cathode with the formed coating was separated, thoroughly washed with distilled water, and dried to the constant weight. The synthesized films were of lilac color, which confirms the presence of incorporated gold particles.

\section{Results and discussion}

During the electrolysis of aqueous or water-ethanol solutions of VT and CA or their mixtures at various ratios in the presence of $\mathrm{HAuCl}_{4}$ and chitosan, nanocomposites and nanocomposite coatings with a gold content of 1-10 wt.\% are formed only in the presence of a peroxide-type initiator, for example, TBOBA, at the potential of electroreduction of $0.6-1.2 \mathrm{~V} v \mathrm{vs}$. $\mathrm{Ag} / \mathrm{AgCl}$.

After drying, the formed nanocomposite coatings on the electrodes become insoluble in water and in commonly used organic solvents (DMSO, DMFA, acetonitrile, etc.). The copolymer is crosslinked upon heating. In the electronic spectra of gold-containing nanocomposites, in contrast to aqueous solutions of the initial copolymers and $\mathrm{HAuCl}_{4}$, plasmon absorption bands appear with a maximum in the region of nanocomposite coatings containing gold. In Figure 1, absorption bands appear with a maximum in the region of 517-521 nm, which is typical for systems with zero-valent gold.

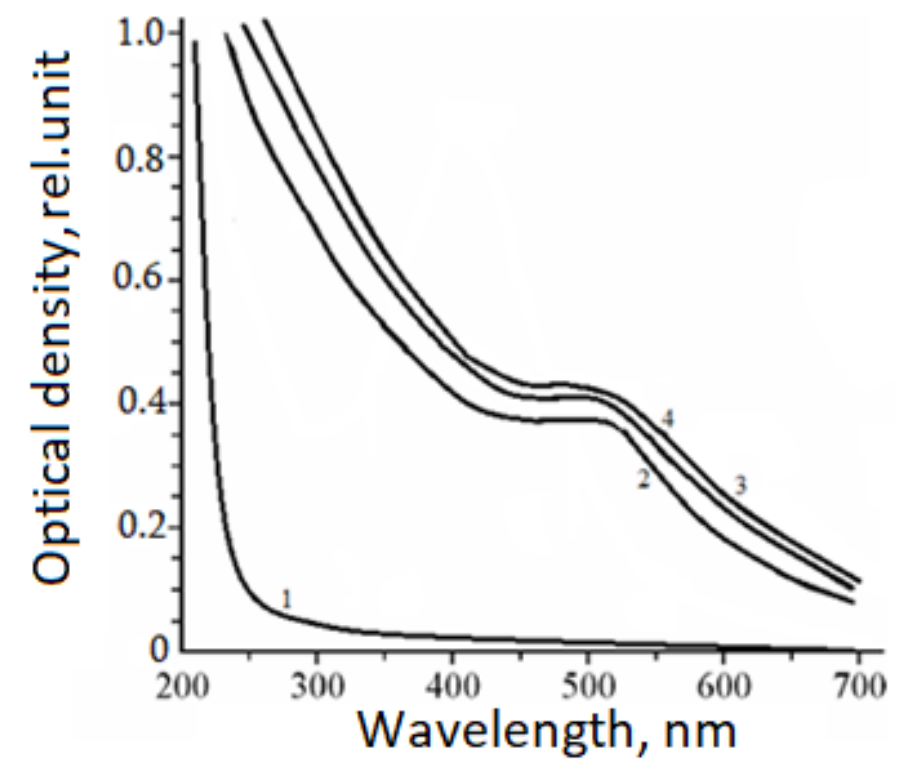

Figure 1. Electronic absorption spectra of VT-CA copolymer (1), gold 6.8 wt.\% (2), gold 7.3 wt.\% (3), gold 8.0 wt.\% (4)

The IR spectrum of gold-containing VT-CA copolymer shown in Figure 2 contains bands corresponding to the frequencies of stretching bending vibrations of the triazole ring at 1503, 1434, $1138,1005,660 \mathrm{~cm}^{-1}(\mathrm{C}-\mathrm{N}, \mathrm{C}=\mathrm{N}), 1275 \mathrm{~cm}^{-1}(\mathrm{NN}), 3106 \mathrm{~cm}^{-1}(\mathrm{CH})$, and a band at $1711 \mathrm{~cm}^{-1}$ related to stretching vibrations of the units of the carboxyl group.

Analysis of IR spectra shows that the formation of gold-containing polymer nanocomposites leads to insignificant changes in the chemical structure of the copolymer matrix. Thus, the intensities of the absorption bands of the triazole ring, which can act as coordination centers of gold nano- 
particles, show a weak shift (by $3-4 \mathrm{~cm}^{-1}$ ) of one band at $1506 \mathrm{~cm}^{-1}$, which is characteristic of the stretching vibrations of the ring $(\mathrm{C}-\mathrm{N}$ and $\mathrm{C}=\mathrm{N})$.

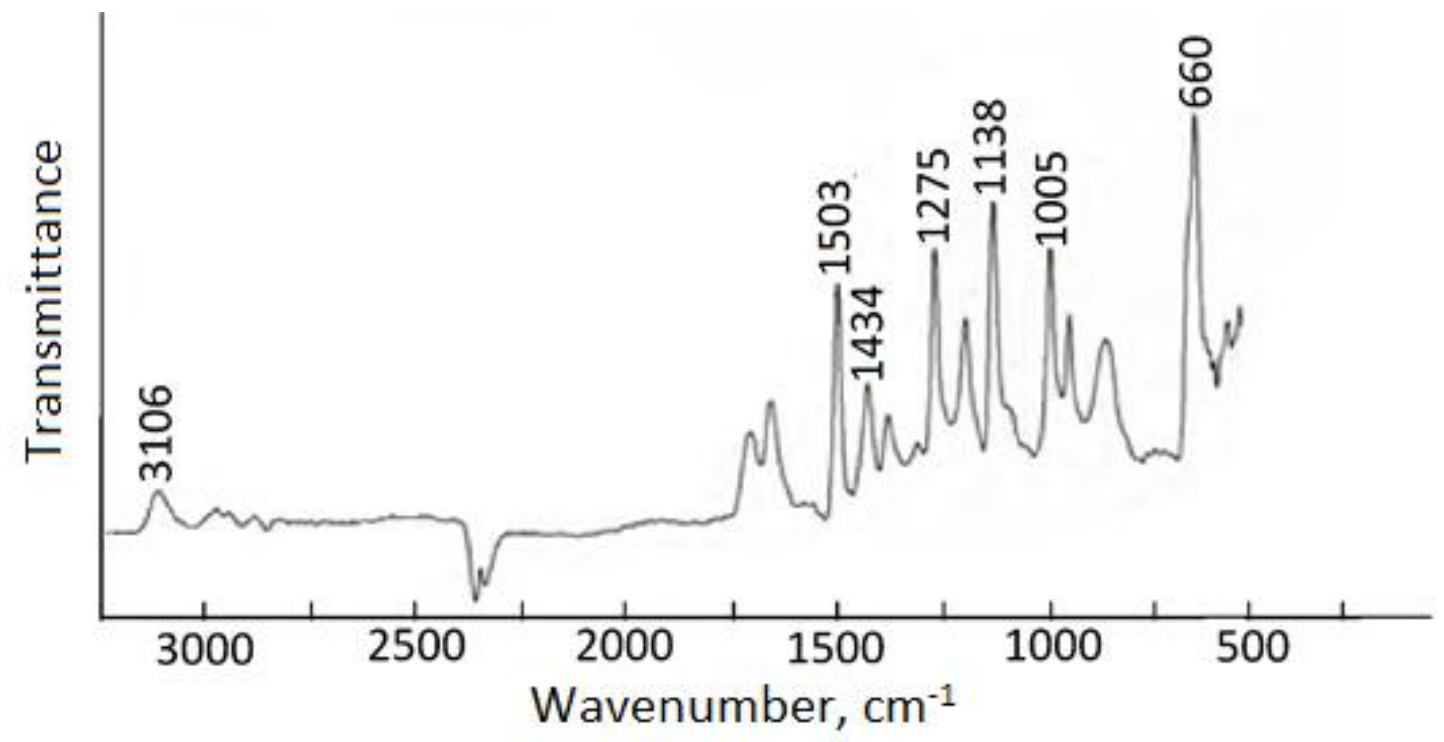

Figure 2. IR spectrum of gold nanocomposite based on VT-CA copolymer

This shift may indicate the coordination interaction of the triazole ring with the surface atoms of metal nanoparticles. An intense band in the IR spectra of the copolymers at $1711 \mathrm{~cm}^{-1}$ indicates that the carboxyl group of CA in the copolymers is in unionized form. When passing from copolymers to nanocomposites with gold nanoparticles, it can be seen that the number of non-ionized carboxyl groups $(-\mathrm{COOH})$ decreases significantly, and a new absorption band appears at $1577 \mathrm{~cm}^{-1}$, which is characteristic of stretching vibrations of the carboxylate anion $\left(-\mathrm{COOH}^{-}\right)$.

The gold content in nanocomposite films was 1-8 \%, according to the data of elemental analysis and atomic absorption spectroscopy. The intrinsic viscosity of polymer nanocomposites, in contrast to the initial copolymers, increased by an average of $10-20 \%$, which can be explained by the presence of numerous bonds of polymer macromolecules with metal nanoparticles (Table 1 ).

Table 1. Nanocomposites based on VT-CA copolymers

\begin{tabular}{ccccccc}
\hline Nanocomposite & $E / \mathrm{V}$ & Au content, wt. \% & Yield, \% & $\eta / \mathrm{dl} \cdot \mathrm{g}^{-1}$ & $\lambda_{\max } / \mathrm{nm}$ & Nanoparticle sizes, $\mathrm{nm}$ \\
\hline 1 & -0.60 & 6.8 & 73.4 & 1.52 & 521 & $2-10$ \\
\hline 2 & -0.75 & 7.3 & 78.5 & 0.83 & 517 & $4-6$ \\
\hline 3 & -0.90 & 8.0 & 80.1 & 0.19 & 517 & $2-4$ \\
\hline
\end{tabular}

As can be seen from the results, with an increase in the cathodic potential, the metal content in the nanocomposite increases while the size of the nanoparticles decreases. Coordination occurs due to the nitrogen atoms of the heterocycle. As a result of this work, a nanocomposite of the following structure presented in Scheme 1 is formed.

The solubility of nanocomposites is mainly due to the intramolecular interaction of copolymer macromolecules with gold nanoparticles, due to which relatively loose polymer coils are formed rather unfolded in an aqueous solution since a small amount of nanoparticles participates in the coordination interaction. Polymer coils represent a more compact conformational state of macromolecules of a polymer nanocomposite, in comparison with the initial copolymer, which arises due to partial crosslinking by nanosized particles. 

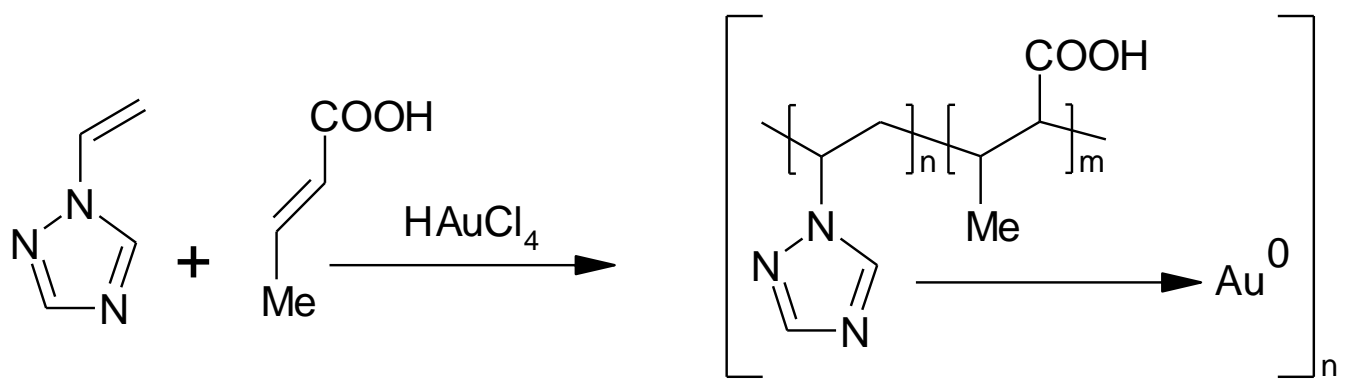

Scheme 1. Nanocomposite structure

An increase in gold content over $8 \mathrm{wt} . \%$ leads first to a partial and then to a complete loss of solubility. This is due to the enhancement of intermolecular interaction and crosslinking of polymer macromolecules by metal nanoparticles under the influence of multiple cooperative forces. In this case, the intermolecular binding of macromolecules with the surface atoms of gold nanoparticles affects the hydration of the copolymer. The solubility of the copolymer is due to the formation of hydrogen bonds of the triazole ring and carboxyl groups [38,39] (hydrophilic hydration is characteristic of poly-1-vinyl-1.2.4-triazole). Thus, with an increase in the content of gold nanoparticles, the hydration of the polymer nanocomposite decreases down to its complete loss (most of the triazole and carboxyl groups are involved in coordination interaction with gold nanoparticles and do not participate in the formation of hydrogen bonds with water molecules). The formation of organoinorganic nanocomposites, namely the presence of gold nanoparticles and an amorphous polymer phase, is confirmed by the results of X-ray phase analysis. The approximate sizes of metal nanoparticles are presented by the results of $\mathrm{X}$-ray phase analysis shown in Figure 3.

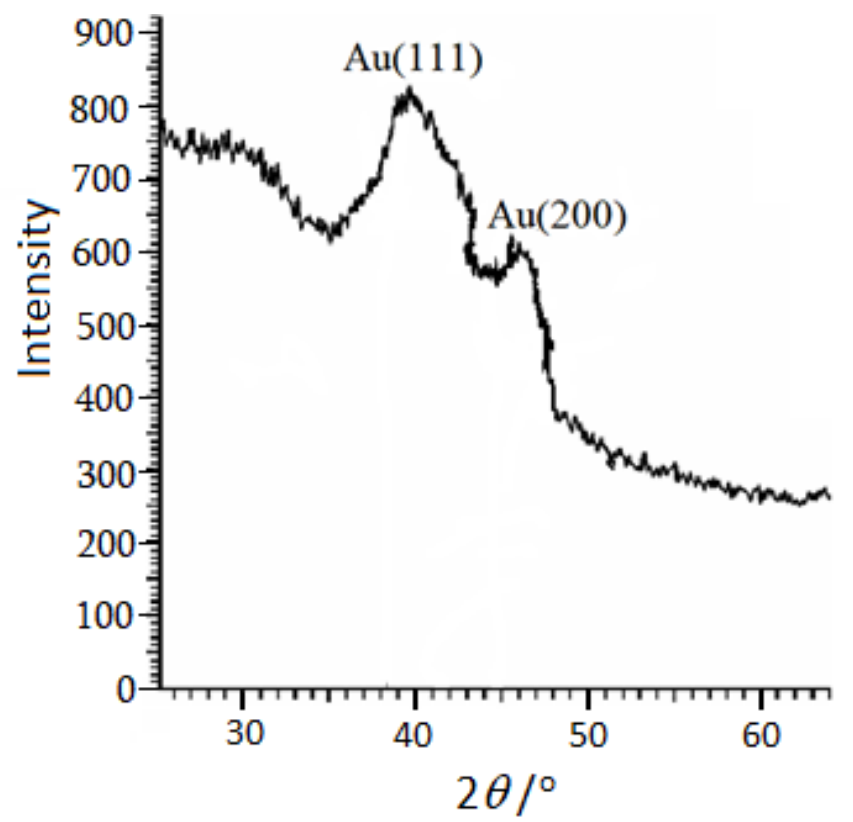

Figure 3. Fragment of the diffractogram of gold nanocomposite

In the region where the gold particle $\mathrm{Au}(111)$ has $d=0.235 \mathrm{~nm}$, a strongly broadened maximum is observed in the diffractogram of the composite, which confirms the presence of metallic gold in the nanosized state in the studied samples.

The sizes of gold nanoparticles were calculated according to [40]. According to the results of transmission electron microscopy (Figure 4), nanocomposite contains mostly elliptical gold nanoparticles, uniformly distributed in the copolymer matrix, having sizes of $2-10 \mathrm{~nm}$. 

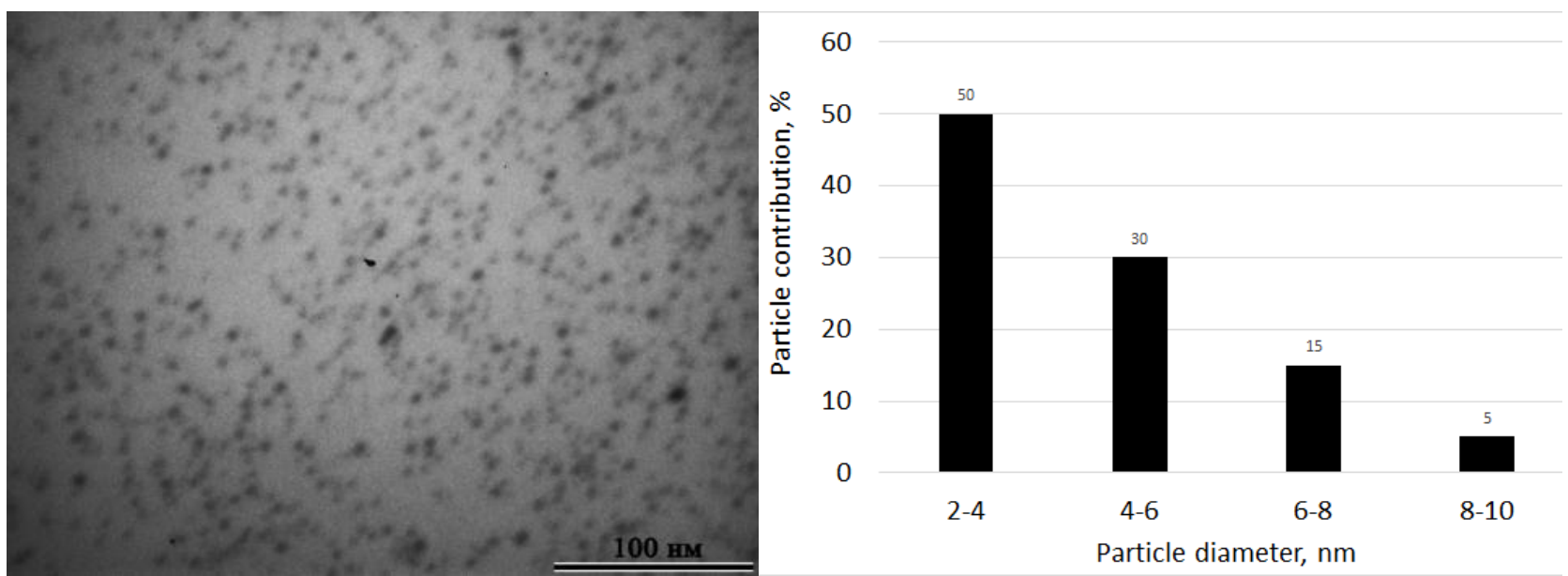

Figure 4. Electron micrograph (left) and distribution diagram of gold nanoparticles by size (right) in VT-CA copolymer matrix

The study of the thermal stability of polymer nanocomposites showed that the first stage of polymer matrix destruction is observed in the temperature range from 280 to $400{ }^{\circ} \mathrm{C}$ and is accompanied by a gradual weight loss down to $40 \%$, which refers to the elimination and oxidation of carboxyl and methyl groups (Figure 5).

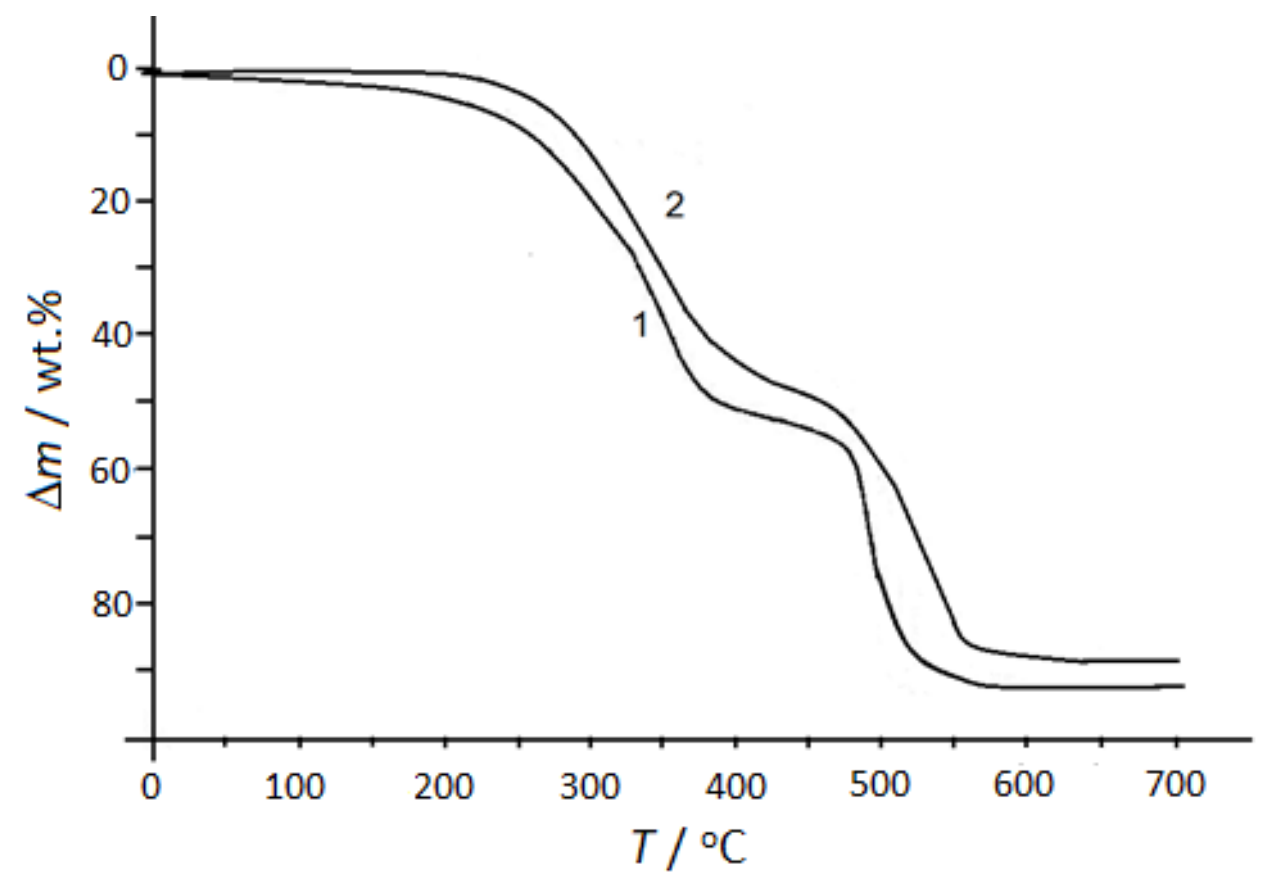

Figure 5. Thermogravimetric curves: 1-copolymer VT-CA, 2 - gold-bearing nanocomposite

The next stage of decomposition of the composite occurs in the temperature range $480-570{ }^{\circ} \mathrm{C}$. The gold-containing nanocomposite is thermally more stable than the copolymer, since denser coils of the nanocomposite with the metal are formed.

The electrical conductivity of nanocomposite polymer films based on VT-CA copolymers increases by three orders of magnitude, up to $8.9 \times 10^{-10}-7.2 \times 10^{-9} \mathrm{~S} \mathrm{~m}^{-1}$, in comparison with the original copolymers. Pure VT-CA copolymer has no electrical conductivity. The increase in electrical conductivity is apparently due to the contribution to the total electrical conductivity of individual local tunneling currents arising in these samples between electrically conducting metallic gold nanoparticles closely located in the dielectric polymer matrix. 


\section{Conclusion}

Based on monomeric VT-CA systems, nanocomposites and nanocomposite coatings have been synthesized electrochemically. It was found that, depending on the electrode potential, the nanoparticle size changes from 2 to $10 \mathrm{~nm}$, and the viscosity from 0.19 to $1.52 \mathrm{dl} \mathrm{g}^{-1}$. According to the transmission electron microscopy data, the gold nanoparticles are uniformly distributed over the polymer matrix. The composition and structure of the obtained nanocomposites have been investigated. The synthesized nanocomposites can be used in medicine as thromboresistant, biocompatible polymers.

Acknowledgements: This study was supported by the Ministry of Education, Science, Culture and Sports RA, Science Committee (project no. 21T-2E068).

\section{References}

[1] A. D. Pomogailo, A. S. Rosenberg, I. E. Uflyand, Metal Nanoparticles in Polymers, Khimiya, Moscow, Russia, 2000.

[2] C. N. R. Rao, A. Müller, A. K. Cheetham (Eds.), The Chemistry of Nanomaterials: Synthesis, Properties and Applications, Wiley-VCH Verlag GmbH \& Co. Weinheim, Germany, 2004. ISBN 3-527-30686-2.

[3] P. Broz (Ed.), Polymer-Based Nanostructures: Medical Applications, Roy. Soc. Chem. Pub., Cambridge, UK, 2010.

[4] M. Noroozi, A. Zakaria, M. M. Moksin, Z. A. Wahab, A. Abedin, International Journal of Molecular Sciences 13(7) (2012) 8086-8096. https://doi.org/10.3390/ijms13078086

[5] S. H. Sargsyan, K. S. Margaryan, Russian Journal of General Chemistry 84 (2014) 550-551. https://doi.org/10.1134/S1070363214030232

[6] A. Tiwari (Ed.), Recent Developments in Bio-Nanocomposites for Biomedical Applications, Nova Science Publishers Inc., New York, USA, 2011, p. 511. ISBN 13: 9781617615139

[7] L.-S. Wang, C.-Y. Wang, C.-H. Yang, C.-L. Hsieh, S.-Y. Chen, C.-Y. Shen, J.-J. Wang, K.-S. Huang International Journal of Nanomedicine 10(1) (2015) 2685-2696. https://doi.org/10.2147/IJN.S77410

[8] G.F. Prozorova, A.S. Pozdnyakov, A.I. Emel'Yanov, S.A. Korzhova, T.G. Ermakova, B.A. Trofimov, Doklady Chemistry 449(1) (2013) 87-88. https://doi.org/10.1134/S0012500813030051

[9] R.A. Hule, D.J. Pochan. MRS Bulletin 32(4) (2007) 354-358. https://doi.org/10.1557/$\underline{\text { mrs2007.235 }}$

[10] F. Liebig, R. M. Sarhan, M. Bargheer, C. N. Z. Schmitt, A. H. Poghosyan, A. A. Shahinyan, J. Koetz, RSC Advances 10(14) (2020) 8152-8160. https://doi.org/10.1039/DORA00729C

[11] A. V. Meltonyan, A. H. Poghosyan, S. H. Sargsyan, K. S. Margaryan, A. A. Shahinyan Colloid and Polymer Science 297 (2019) 1345-1352. https://doi.org/10.1007/s00396-019-04554-x

[12] A. V. Meltonyan, A. H. Poghosyan, S. H. Sargsyan, K. S. Margaryan, A. A. Shahinyan, Journal of Polymer Research 27 (2020) 91. https://doi.org/10.1007/s10965-020-02075-8

[13] A. S. Pozdnyakov, N. P. Kuznetsova, S. A. Korzhova, T. G. Ermakova, T. V. Fadeeva, A. V. Vetohina, G. F. Prozorova, Russian Chemical Bulletin 64 (2015) 1440-1444. https://doi.org/10.1007/s11172-015-1029-9

[14] S. H. Sargsyan, K. S. Margaryan, A. S. Sargsyan, Russian Journal of Applied Chemistry 91 (2018) 310-313. https://doi.org/10.1134/S1070427218020210

[15] J. S. Kim, E. Kuk, K. N. Yu, J.-H. Kim, S. J. Park, H. J. Lee, S. H. Kim, Y. K. Park, Y. H. Park, C.-Y. Hwang, Y. -K. Kim, Y.-S. Lee, D.H. Jeong, M.-H. Cho. Nanomedicine: Nanotechnology, Biology and Medicine 3(1) (2007) 95-101. https://doi.org/10.1016/i.nano.2006.12.001 
[16] M. Rai, A. Yadav, A. Gade. Biotechnology Advances 27(1) (2009) 76-83. https://doi.org/10.1016/i.biotechadv.2008.09.002

[17] C. A. Mecha, V. L. Pillay, Journal of Membrane Science 458 (2014) 149-156. https://doi.org/10.1016/i.memsci.2014.02.001

[18] E. F. Panarin, Russian Chemical Bulletin 66(10) (2017) 1812-1820. https://doi.org/10.1007/s11172-017-1952-z

[19] A. S. Pozdnyakov, A. A. Ivanova, A. I. Emelyanov, T. G. Ermakova, G. F. Prozorova, Russian Chemical Bulletin 66 (2017) 1099-1103. https://doi.org/10.1007/s11172-017-1860-2

[20] V. V. Kopeikin, E. F. Panarin, Doklady Chemistry 380(4-6) (2001) 277-279. https://doi.org/10.1023/A:1012396522426

[21] M. Davoodbasha, S.-C. Kim, S.-Y. Lee, J.-W. Kim, Archives of Biochemistry and Biophysics 605 (2016) 49-58. https://doi.org/10.1016/i.abb.2016.01.013

[22] L. A. Tatarova, T. G. Yermakova, Al. Al. Berlin, Ye. F. Razvodovskii, V. A. Lopyrev, N. F. Kedrina, N. S. Yenikolopyan, Polymer Science U.S.S.R. 24(10) (1982) 2529-2536. https://doi.org/10.1016/0032-3950(82)90127-7

[23] G. F. Prozorova, S. A. Korzhova, T. V. Kon'kova, A. S. Pozdnyakov, T. G. Ermakova, T. V. Fadeeva, S. A. Vereshchagina, B. A. Trofimov, Russian Chemical Bulletin 60 (2011) 671. https://doi.org/10.1007/s11172-011-0104-0

[24] K. S. Margaryan, S. H. Sargsyan, A. S. Sargsyan, Russian Journal of Applied Chemistry 89 (2016) 1261-1264. https://doi.org/10.1134/S1070427216080073

[25] H. Hirai, N. Toshima, Polymer-attached catalysis in Tailored Metal Catalysts, Iwasawa, Ed., D. Reidel Pub. Co., Dordrecht, Holand, 1985, pp. 87-140. https://doi.org/10.1007/978-94009-5261-4 2

[26] A. D. Pomogailo, A. S. Rozenberg, G. I. Dzhardimalieva, Russian Chemical Reviews 80(3) (2011) 257. http://dx.doi.org/10.1070/RC2011v080n03ABEH004079

[27] V.I. Roldugin, Russian Chemical Reviews 69(10) (2000) 821. https://dx.doi.org/10.1070/RC2000v069n10ABEH000605

[28] M.-C. Daniel, D. Astruc, Chemical Reviews 104 (1) (2004) 293-346. https://doi.org/10.1021/cr030698+

[29] V. V. Volkov, T. A. Kravchenko, V. I. Roldughin, Russian Chemical Reviews 82(5) (2013) 465. https://doi.org/10.1070/RC2013v082n05ABEH004325

[30] B. I. Kharisov, O. V. Kharissova, U. Ortiz-Méndez, Handbook of Less Common Nanostructures, CRC Press, Taylor and Francis Group, Boca Raton, 2012, p. 828.

[31] P.C. Lee, D. Meisel, The Journal of Physical Chemistry 86(17) (1982) 3391-3395. https://doi.org/10.1021/j100214a025

[32] P. Yang, W. Zhang, Y. Du, X.J. Wang, Journal of Molecular Catalysis A: Chemical 260(1-2) (2006) 4-10. https://doi.org/10.1016/i.molcata.2006.06.045

[33] E. J. Kim, J. H. Yeum, H. D. Ghim, S. G. Lee, G. H. Lee, H. J. Lee, S. I. Han, J. H. Choi, Polymer (Korea) 35(2) (2011) 161-165. https://www.cheric.org/PDF/PK/PK35/PK35-2-0161.pdf

[34] S. V. Vasilyeva, M. A. Vorotyntsev, I. Bezverkhyy, E. Lesniewska, O. Heintz, R. Chassagnon, The Journal of Physical Chemistry C 112(50) (2008) 19878-19885. https://doi.org/10.1021/ip805423t

[35] O. A. Petrii, Russian Chemical Reviews 85(2) (2015) 159. http://dx.doi.org/10.1070/RCR4438

[36] Z.-Y. Zhou, N. Tian, J.-T. Li, I. Broadwell, Sh.-G. Sun Chemical Society Reviews 40 (2011) 41674185 https://doi.org/10.1039/COCS00176G

[37] G. F. Prozorova, A. S. Pozdnyakov, S. A. Korzhova, T. G. Ermakova, M. A. Novikov, E. A. Titov, L. M. Sosedova, Russian Chemical Bulletin 63 (2014) 2126-2129. https://doi.org/$\underline{10.1007 / s 11172-014-0709-1}$ 
[38] N. L. Mazyar, V. Annenkov, V. A. Kruglova, S. M. Anan'ev, E. N. Danilovtseva, A. V. Rokhin, S. V. Zinchenko, Russian Chemical Bulletin, International Edition 49(12) (2000) 2013-2017. https://doi.org/10.1023/A:1009571908805

[39] A. S. Pozdnyakov, A. I. Emel'yanov, T. G. Ermakova, G. F. Polymer Science B 56 (2014) 238246. https://doi.org/10.1134/S1560090414020122

[40] Ch. S. Barrett, T. B. Masalsky, The structure of metals, Metallurgy, Moscow, USSR, 1984, p. 681

(C2022 by the authors; licensee IAPC, Zagreb, Croatia. This article is an open-access article distributed under the terms and conditions of the Creative Commons Attribution license (https://creativecommons.org/licenses/by/4.0/) 